\section{Self injection with mercury}

A 23 year old man with a history of depression claimed to have injected himself with mercury from a sphygmomanometer six weeks before. Four days before admission he had developed pleuritic pain, exertional dyspnoea, and malaise. His temperature was $38^{\circ} \mathrm{C}$, and he had a low posterior right pleural rub. A plain chest radiograph showed a large collection of mercury at the apex of his heart with small opacities in the lung fields (figure). There were similar opacities in the sacral area and along the left forearm. Catheterisation of the right heart was performed, but only $1 \mathrm{ml}$ of mercury was aspirated. The patient's plasma concentration of mercury rose, and he was transferred to a toxicology unit for treatment with chelating agents. Deliberate injection of mercury has been reported before. ${ }^{12}$ The mercury around the sacrum probably passed under gravity from the right atrium to the pelvic veins. ${ }^{3}$ The left forearm was presumably the site of injection. - J R CLAGUE, $\mathrm{H}$ H GRAY, P H KAY, departments of cardiology and cardiothoracic surgery, Brompton Hospital, London SW3 6HP

1 Celli B, Khan MA. Mercury embolisation of the lung. $N$ Engl f Med 1976;295:883-5.

2 Cassar-Pullicino VN, Taylor DN, Fitzpatrick MB. Multiple mercury emboli. Br $\mathcal{F}$ Radiol $1985 ; 58: 470-4$

3 Stahl MG, Bonekat DU, Shigeoka JW. Concomitant pulmonary thromboembolism and metallic mercury embolism. Chest 1985;88:787-9.

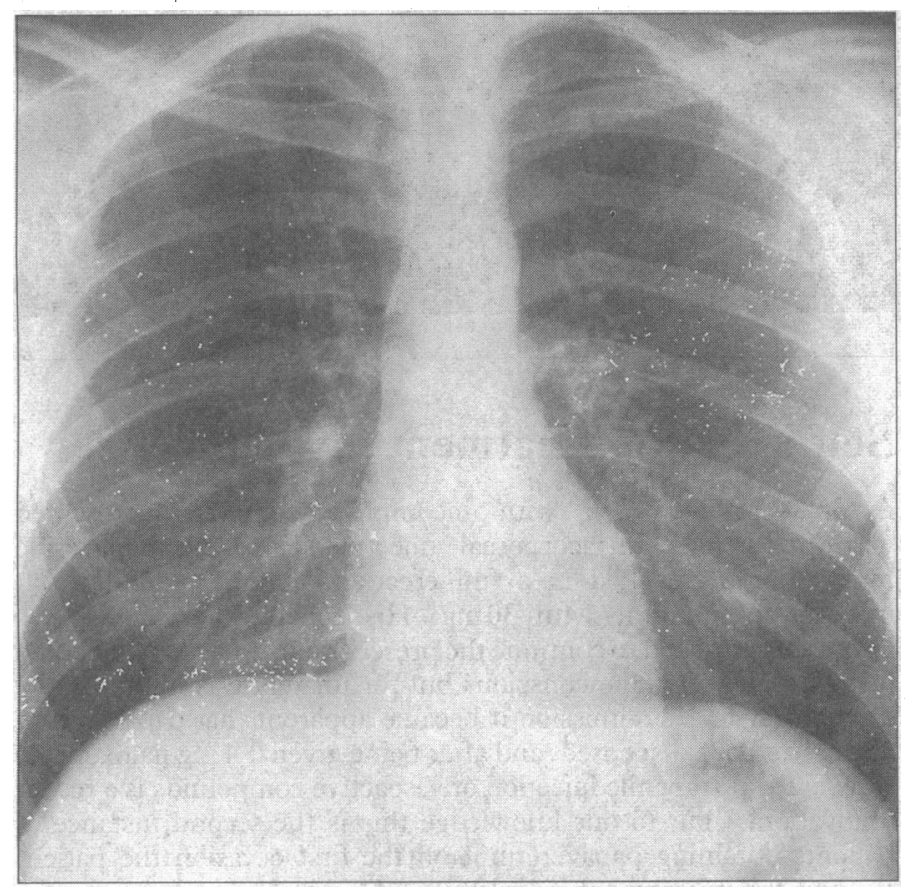

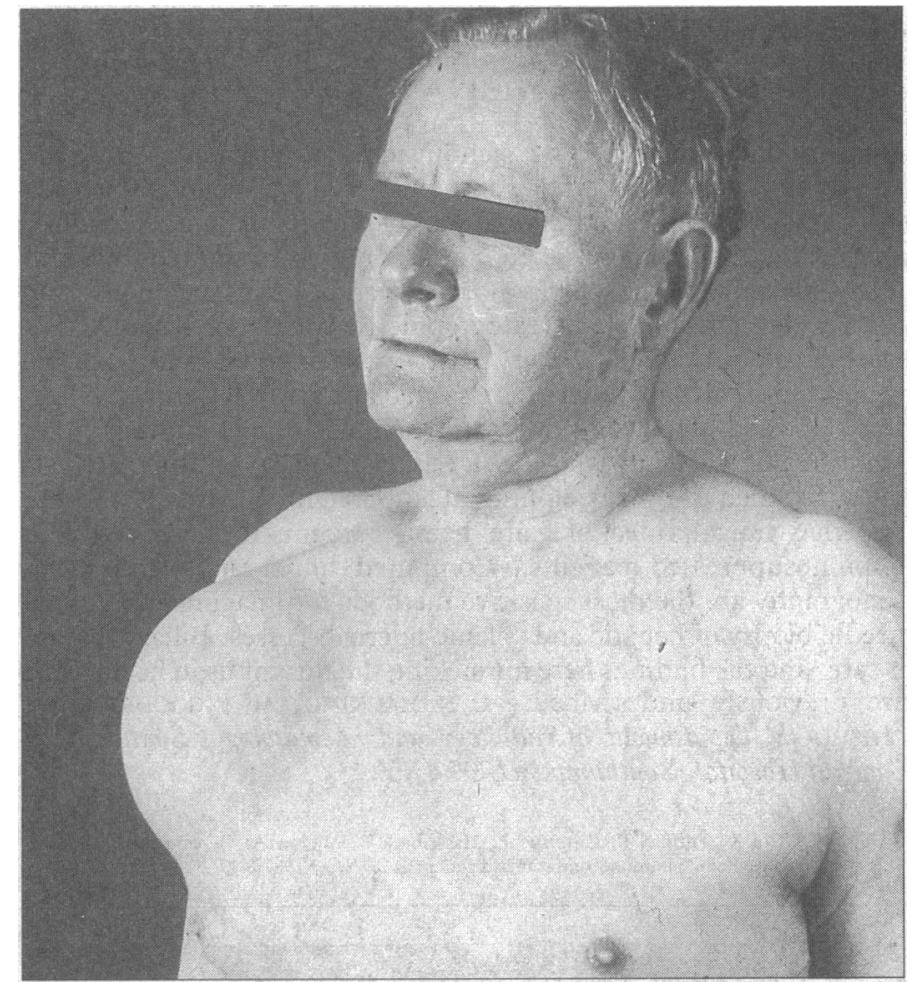

\section{Unusual soft tissue tumour}

A 69 year old man presented with a long history of an enlarging swelling in his right anterior chest wall. He had had a repair of a dislocated right shoulder 32 years before. He had a firm, tender mobile mass (figure) with overlying venous dilatation but no lymphadenopathy. A computed tờmogram showed a well circumscribed mass arising from the pectoralis major muscle, and a soft tissue sarcoma was suspected. At operation a cystic mass was removed. The final swab count showed that there was an extra swab in the count. When the cyst was examined histologically the findings were compatible with a reaction to a foreign body.

Putting radio-opaque markers into swabs was not widespread until the 1940s. ${ }^{1}$ The longest retention of. a foreign body reported previously was 30 years. $^{2}$ - A C MACEY, J X O'CONNELL, T M O'BRIEN, Cappagh Orthopaedic Hospital, Dublin 11

1 Olnick HM, Weens HS, Rogers JV. Radiological diagnosis of retained surgical sponges. fAMA 1955;159:1525-7.

2 Crossen HS, Crossen DF. Foreign bodies left in the abdomen. CV Mosby: St Louis, 1940

\title{
The airport assault syndrome on the increase
}

Increase in air travel exposes all travellers to direct assaults on their Achilles tendon from trolleys constructed as Roman chariots and used as battering rams. We examined three patients after they had been struck by an advancing trolley. In two the findings were minimal, though the victims complained of severe pain and an inability to bear weight. The third patient suffered an immediate haematoma associated with swelling and severe pain. A change in chariot design is necessary to protect the public from this plague. Regulations stipulate the size and weight of baggage that each traveller may have, but there is no reason why suitcases must lie flat on the trolley. If they are stood on their sides the trolley need not be more than $35 \mathrm{~cm}$ long (figure). The ease in manoeuvring a shorter vehicle may prevent many travellers from grievous bodily harm at the hands of unsuspecting charioteers, occasionally resulting in fractures of long bones. Should a shorter vehicle prove unacceptable one could consider "putting the horse before the cart," which would certainly bring the epidemic under control because of the incorporated self destructive mechanism. - MICHAEL HEIM, ABRAHAM OHRY, MORRIS AZARIA, rehabilitation departments, Chaim Sheba Medical Centre, Tel Hashomer, Israel

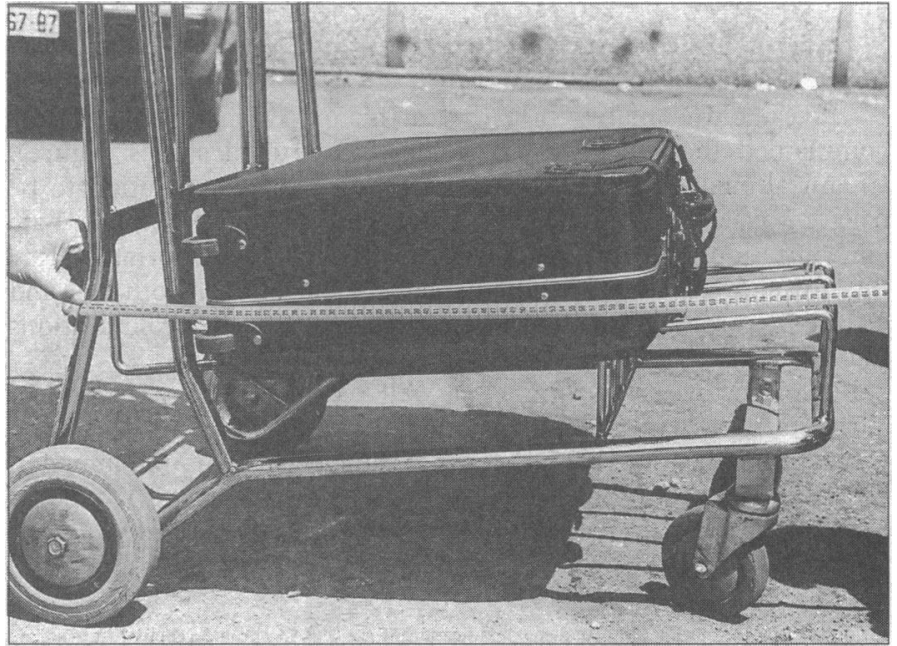

